\title{
Sulitar Irrigation System: Struggle from Poverty to Prosperity
}

\section{Krishna Prasad Rijal}

\begin{abstract}
Nepal has glorious history with tens of thousands of self sustainable farmer managed irrigation systems, which accounts for about two third of total irrigated area in the country. Sulitar Irrigation System, located in Chitwan district of Nepal and constructed almost two decades ago, is one of them. The farmers have been relentlessly working for construction, maintenance, repair and operation of the system with wider community participation. Participation is not only limited to the field level but also extends to crafting of rules and regulation pertaining to the governance of the system. Participatory approach adopted in this system has fostered transparency and accountability in the management entity with a sense of ownership and selfresponsibility as an asset embraced by water users. In addition, effective system of resource mobilization for Operation and Maintenance $(O \& M)$ is appreciable. Their working culture of participation, purposefulness and integrity has drawn in huge amount of internal as well as external resources to the project. Efficient networking with other organizations has led to profound resource mobilization, leadership sharing and a buildup of strong social capital. They are also well aware of the sustainability of the system and pre-requisites for it. Resource generation and $\mathrm{O} \& \mathrm{M}$ of the system have been institutionalized for its durability and long-term sustainability.

Fundamental requirement for an irrigation system is the impact made by the system on the agriculture and livelihood of the people within the command area. Subsistence based agriculture prevailing before the service of irrigation system has now advanced to crop intensification and crop diversification paving the way for commercialization. Food security in the community has been enhanced and poor livelihood of common people has been transforming towards prosperity.
\end{abstract}

Keywords: Sulitar Irrigation System, Chitwan, FMIS, Poverty, WUA, Nepal

\section{Introduction}

$\mathbf{T}^{\mathrm{t}}$ is proclaimed that irrigation has high potential 1 to alleviate poverty. Irrigation is supposed to transform subsistence based agriculture to commercialized agriculture. New wage employment in irrigated agriculture, construction work and the increase of local demand for goods and services as spin-off of irrigation development would further benefit the rural poor (Van Koppen et al., 2002). Similarly, organization mobilization, empowerment and institutionalization mechanism set to address the inequity and injustice can support the poor and poverty reduction (Paudel, 2010). Irrigated agriculture can reduce poverty through primary, secondary and tertiary effects. Primarily, through increased yield and production, food security can be enhanced. Secondarily, through labor wage increase and food price decrease, the poor can get advantage of earning livelihood from irrigated agriculture. Similarly, the impact on trade and industries induced by the development of irrigated agriculture provide employment opportunities to the landless, small land holders and marginalized people and ultimately enhances the overall economic development of the country.

Agriculture is perhaps the only sector, which can effectively transform the livelihood of rural poor in Nepal. In Nepalese context, poverty level of people from irrigated area has decreased more than that of people from non-irrigated area (Paudel, 2010). Similarly, as reported by AED (2009), the cropping intensity due to investment in small irrigation has increased by 46 percentage point $(157 \%-211 \%)$.

Retrospect of the agrarian history of the country shows that farmers had constructed irrigation canals on their own, which we call today Farmer Managed Irrigation System (FMIS). Almost 67 percent of irrigated areas in Nepal are farmer managed, which counts more than 17000 no. of systems (Pradhan, 1989).

Most of FMIS in Nepal are self-sustaining even without any external supports. They are endowed with the templated attributes of successful irrigation systems. They are institutionally sound and financially sustainable. The strong social capital in these systems has compensated the weakness in physical system. Sulitar Irrigation System is also one of the successful FMIS, located in Shaktikhor Village Development Committee (VDC) of Chitwan district in Nepal. Since the initiation of canal construction 20 years ago, they have been relentlessly working for maintaining and upgrading the system. Till date, they have mobilized millions of cash fund and thousands of labor-days. They have not only constructed the physical system, but also maintained and managed the system for smooth operation. Networking and establishment of linkages are another appreciable effort of the Water Users Association (WUA). The traditional subsistence based agriculture is advancing towards commercialization through crop intensification and crop diversification. A distinct change in the livelihood of people can be seen. This paper shed lights on some pertinent features of this system, which can be the matter of learning and the source of inspiration for the systems in similar context. This study is based on literature review, information from key informants and focused group discussion with the beneficiary farmers and WUA members. 


\section{Irrigation System Background}

Sulitar Irrigation System is a farmer managed system,which lies at ward no. 5 and 6 of Shaktikhor VDC in Chitwan district. Construction of this system was initiated by farmers themselves in 1992 A.D. Initially, people of Sulitar village ward no. 5 of Shaktikhor VDC, decided to construct a canal to deliver water from Shakti Khola to their village. They collected NRs 55000 (\$550) as Bighatti (equity fund) from the beneficiary farmers. After a rigorous and dogged effort of three years, they started irrigating at the head reaches of canal. People who used to sow millet, pulses began to transplant rice. Cropping intensity and crop production began to increase. Overall food security was enhanced. In 1994, inspired by these changes, some people of ward no. 5 and most people of ward no. 6 held a meeting and discussed to extend the canal system to their farms too. They proposed to the existing beneficiaries of Sulitar to share their initial investment of NRs 55000 by them all and to extend the system to their farm land. People of Sulitar village accepted the proposal. Then the existing and the new users all again started to construct the canal. They raised labor contribution as one labor from each Kathha (one $30^{\text {th }}$ of a hectare) land to be irrigated. Additionally, they raised funds from various organizations. After continuous effort of ten years, they started irrigating the extended farm land of ward no. 5 and 6 since 2004. Since then, agricultural scenario of the area has changed. Partially cultivated farm land is cultivated almost round the year. Increased production of cereals and introduction of cash crops and vegetables have rife everywhere. Livelihood of people has changed with increased income and agricultural production. They have earned social capital in the community. They own millions of physical assets in the canal system. The salient features of this system are presented in Table 1.

\begin{tabular}{|l|l|}
\hline \multicolumn{1}{|c|}{$\begin{array}{c}\text { Name of Irrigation } \\
\text { System }\end{array}$} & \multicolumn{1}{|c|}{ Sulitar Irrigation System } \\
\hline Location & $\begin{array}{l}\text { Shaktikhor VDC, Ward No. 5 and } \\
\text { 6, Chitwan }\end{array}$ \\
\hline Command Area & 93 ha \\
\hline Source of system & Shaktikhola \\
\hline Length of canal & $4.8 \mathrm{~km}$ \\
\hline Number of canal structures & 32 \\
\hline $\begin{array}{l}\text { Name of Water Users } \\
\text { Association }\end{array}$ & $\begin{array}{l}\text { Sulitar Canal Water User } \\
\text { Association }\end{array}$ \\
\hline Number of Household & 245 \\
\hline Population & 1100 \\
\hline
\end{tabular}

Table 1: Salient features of Sulitar Irrigation System

(Source: CIDD No. 5; Sulitar WUA)

\section{Location of Irrigation System}

This system lies at ward no. 5 and 6 of Shaktikhor VDC in Chitwan district. The canal water source is Shakti khola and the intake is located at $27^{\circ} 44^{\prime} 19^{\prime \prime} \mathrm{N}, 84^{\circ}$ $35^{\prime} 52.7^{\prime \prime}$ E, 389m amsl. The sub-project command area lies in near Milan bazaar of Shaktikhor VDC.The project area lies at $28 \mathrm{~km}$ north-east of Bharatpur, the district headquarter of Chitwan district. Metalled, gravelled and earthen village road within the subproject provides access and linkage to the command area. Most of the main canal reach and the branch canals can be approached through the existing village road. The command area of the system is face South East with north-south slope. The location map of the project area is depicted in figure 1.

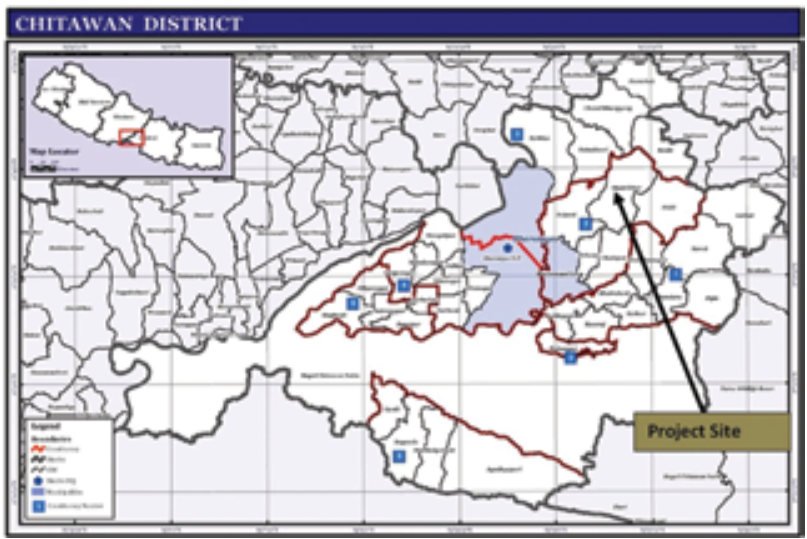

Figure 1: Layout Map of Sulitar Irrigation System (adopted from CIDD-5, 2015)

\section{Existing Condition of Irrigation System}

Despite the continuous effort of farmers to manage and maintain this system, some problems and weaknesses prevail in the physical infrastructures. There are no water control structures at the intake. During rainy season, flood enters the canal and damages the system (Photo 1). Entry of sand and gravel through the intake is also found significant. Along the banks of the canal, the excavated sand and gravel transported from the canal bed can be seen elsewhere. This has led mainly to two problems. Firstly, canal capacity has decreased and secondly, these sand and gravel have eroded the canal bed and the sides, rendering the canal prone to seepage and leakages.

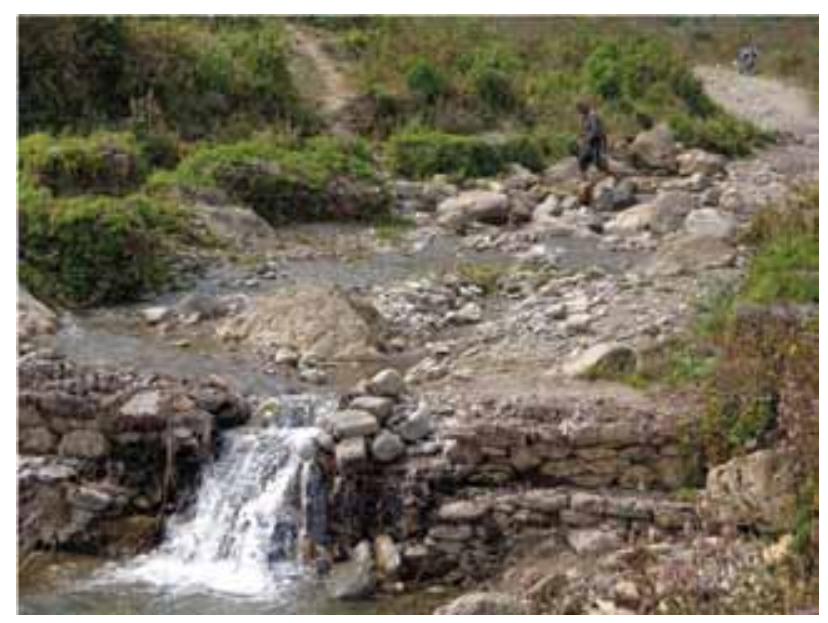

Photo 1: Old Canal Intake. (Photo courtesy: CIDD-5, Chitwan).

The head reach of canal alignment passing alongside the stream is vulnerable due to toe cutting. Canal at this portion is on the verge of toppling to the stream side. The canal also passes through rocky slide prone zones. At the rocky zone, the prevailing canal system is small and therefore water topples through 
those sections. Also, people's movement through these sections is risky due the congested space to walk. On the other hand, the canal reach in the slide prone zone is quite unstable. The canal structures passing though these zones get frequent rupture and damages thus causing seepage through the canal.

\section{Proposed Intervention}

Since this system is reeling under a number of problems, Water Users Association (WUA) made a request to Central Irrigation Development Division No. 5 (CIDD-5), Bharatpur, Chitwan. Realizing difficulties being faced by the irrigation system, users' motivation and prospects of contribution to agriculture, the CIDD- 5 prioritized this system to be implemented under Community Managed Irrigated Area Sector Project-Additional Financing (CMIASPAF) program. This project is under implementation since this year. The major proposed interventions are depicted in Table 2 and the proposed implementation period has been scheduled to be completed within 2017.

\begin{tabular}{|c|l|c|c|c|}
\hline $\begin{array}{c}\text { S. } \\
\text { No. }\end{array}$ & Description & Unit & Quantity & Remarks \\
\hline 1 & Side intake & $n$ & 1 & \\
\hline 2 & Covered canal & $\begin{array}{c}\text { Running } \\
\text { meter }\end{array}$ & 85 & \\
\hline 3 & Super passage & Number & 6 & \\
\hline 4 & Drop Structure & $"$ & 1 & \\
\hline 5 & $\begin{array}{l}\text { Village Road } \\
\text { Bridge }\end{array}$ & $"$ & 4 & \\
\hline 6 & Foot bridge & $"$ & 5 & \\
\hline 7 & $\begin{array}{l}\text { Outlet - One } \\
\text { side }\end{array}$ & $"$ & 8 & \\
\hline 8 & $\begin{array}{l}\text { Aqueduct } 10 \mathrm{~m} . \\
\text { Span }\end{array}$ & $"$ & 1 & \\
\hline 9 & $\begin{array}{l}\text { Aqueduct } 6 \mathrm{~m} . \\
\text { Span }\end{array}$ & $"$ & 1 & \\
\hline 10 & RCC Lining & Running & 945 & \\
\hline
\end{tabular}

Table 2: Proposed Structures (Source: CIDD-5, 2015)

\section{Institutional Setup}

Relatively satisfactory performance and continued sustainability of this irrigation system are considered as the outcome of the water users 'community efforts based on best practiced social norms and values. Location specific settings, farmers' dynamism, support and recognition by state entities as independent and self-governing institutions are the major foundation blocks on which the existence and success of a FMIS rests. Specifics of Sulitar Irrigation System regarding institutional set up are as follows.

\section{Organizational Setup}

Initiation and evolution of this irrigation system has portrayed that the water users are self-motivated and dynamic. At the initiation of the system, they were working in an informal way. Their unity and the participation were bonded by a sort of common need and interest. They used to craft their own rules, regulations and working procedures themselves and complied with them strictly. This informal system didn't pose any hassles in performing their jobs to achieve the set objectives. Nevertheless, later in 2010, they formed and registered a WUA in Central Irrigation Development Division No. 5, Chitwan to be recognized as legal entity and to draw in more external resources. Since then, they have been renewing this organization and working as guided by the provisions made in the constitution. Currently, there are 15 members in WUA. This WUA is inclusive in nature with 5 women members, 3 Dalits (so called untouchable caste) and one Chepang (Severely disadvantaged caste group).

WUA has crafted various rules as governed by their constitution and enforced them strictly. They have formed water distribution and management rules along with the sanction provisions to the violators, provision of appointment of maintenance worker, rules on contribution to the maintenance works and penalty to the non-contributors.

They have also provision of forming various sub committees to assign specific roles to support WUA. Few of these sub committees formed so far are construction and maintenance sub-committee, monitoring sub-committee, water distribution subcommittee etc. Each sub- committee is coordinated by a WUA member. These sub-committees are accountable to WUA for discharging their responsibilities.

\section{Holistic Approach}

People in a community have diverse needs and interests. To fulfill their common need and interest, they aggregate together, often form a group or committee and work on a participatory basis. Users of this irrigation system are not exception to this premise. In addition to irrigation WUA in Sulitar village, there are three community forestry users committees, one agriculture cooperative, a number of agriculture groups and other functional organizations, which work in close coordination and cooperation. Members of WUA also have been found actively involved in those community organizations. The interesting thing is that irrigation leaders are also leading these organizations too. This cooperative culture and linkages among sectoral organizations in community affairs offer a mechanism for information networking and mass participation. This also contributes to leadership and experience sharing. Not only that, integrated co-operative culture offer an opportunity to share their resources. The community of Sulitar village is an excellent example in this regard. Table 3 shows the resources provided by various organizations to this irrigation system.

\section{Resource Mobilization}

Resource mobilization and management are prominent tasks of all irrigation organizations (Martin, 
1986). Sustainability of a community organization is embedded into the resource mobilization capacity of that organization. Resource mobilization capacity, on the other hand, depends on various factors such as the importance of the business in their livelihood, transparency in the participation process, equity on the contribution and benefit sharing and the like. Resources may be in terms of cash, kind or labor. However, contribution of labor by farmer members is the most common form of resource mobilization (Pradhan, 1989). The leaders of Sulitar Irrigation System have played an exemplary role in resource mobilization. They had initiated their project themselves without expecting subsidy from the outsiders and seem to be serious for the continuation of the sustainability of the system. They have been successful in raising funds from various agencies and thousands of labor man-days through themselves. The details of resources collected are depicted in Table 3 .

\begin{tabular}{|c|c|c|c|}
\hline \multirow{2}{*}{$\begin{array}{l}\text { Fiscal } \\
\text { Year }\end{array}$} & \multicolumn{2}{|c|}{$\begin{array}{c}\text { Cash supported by external } \\
\text { agencies }\end{array}$} & \multirow{2}{*}{$\begin{array}{c}\text { Labor } \\
\text { mobilized } \\
\text { by WUA } \\
\text { (man- } \\
\text { days) }\end{array}$} \\
\hline & $\begin{array}{l}\text { Supporting } \\
\text { Agency }\end{array}$ & $\begin{array}{c}\text { Amount } \\
\text { (NRs) }\end{array}$ & \\
\hline \multirow[b]{2}{*}{$2004 / 05$} & VDC & 80000 & \multirow[b]{2}{*}{550} \\
\hline & $\begin{array}{l}\text { District Develop- } \\
\text { ment Committee } \\
\text { (DDC) }\end{array}$ & 100000 & \\
\hline \multirow{3}{*}{$2005 / 06$} & VDC & 100000 & \multirow{3}{*}{652} \\
\hline & $\begin{array}{l}\text { Pragti Community } \\
\text { Forestry (PCF) }\end{array}$ & 100000 & \\
\hline & $\begin{array}{l}\text { Janapragati } \\
\text { Com m un it y } \\
\text { Forestry (JPCF) }\end{array}$ & 65000 & \\
\hline \multirow[t]{2}{*}{$2006 / 07$} & $\begin{array}{l}\text { J a m u n a } \\
\text { C o m m u n i t y } \\
\text { Forestry (JCF) }\end{array}$ & 20000 & \multirow[t]{2}{*}{201} \\
\hline & JPCF & 50000 & \\
\hline \multirow{2}{*}{$2007 / 08$} & PCF & 150000 & \multirow{2}{*}{395} \\
\hline & JCF & 15000 & \\
\hline $2008 / 09$ & PCF & 50000 & 95 \\
\hline \multirow{2}{*}{ 2009/10/11 } & DDC & 500000 & \multirow{2}{*}{1075} \\
\hline & VDC & 200000 & \\
\hline \multirow[b]{2}{*}{$2011 / 12$} & PCF & 50000 & \multirow{2}{*}{$\begin{array}{c}250 \\
35 \text { no. of } \\
\text { gabion } \\
\text { creates }\end{array}$} \\
\hline & $\begin{array}{l}\text { District Land } \\
\text { Conservation } \\
\text { Office }\end{array}$ & & \\
\hline $2012 / 13$ & VDC & 100000 & 205 \\
\hline $2013 / 14$ & VDC & 150000 & 235 \\
\hline
\end{tabular}

Note: $(\$ 1$ = NRs 101.75)

Table 3: Resource Mobilization in Sulitar Irrigation System (Source: Sulitar WUA)

Apart from the external resources, WUA has been able to mobilize internal resources too. Initially, they had raised NRs 55000 as equity fund form the users. Later on, for almost one decade, they continually worked in canal construction with the labor resource of their own. Even after the construction of the canal system too, they have been raising cash and labor resources for canal operation and maintenance works. They now raise NRs 600 per hectare per year as irrigation surface fee, mainly to pay for the canal maintenance worker. Besides, they have been penalizing NRs 500 for the first time water turn violator and NRs 1000 for the second time. Similarly, the absentee labor contribution farmer has to pay NRs 200 per day as a fine. In case of labor contribution, at least 20 labors per hectare land per year is set as a rule. If this much of labor wouldn't suffice, they can increase the contribution as per requirement proportional to the land they own.

\section{Water Management}

Irrigation water allocation and distribution are distinctive and important functions for any irrigation system (Pradhan, 1989). The degree of good water management and satisfaction of users are measuring yardstick of successful management of an irrigation system. Users of Sulitar Irrigation System are aware of potential benefits of a well-managed irrigation system. To accrue maximum benefit from the use of irrigation water, they have forged their own water distribution system on the farm level. A water distribution subcommittee has been formed coordinated by the secretary of WUA. There are 11 members in this subcommittee. They have also crafted various water distribution rules. At present, the following are the major ones:

- Farmers are not allowed to violate water use turn set out by WUA; whoever violate the water turn will be penalized as per the fine set forth.

- Water will be distributed on hourly basis or rotational basis as per discharge available at the source and the demand made by farmers.

- To facilitate the farmers to transplant rice within a short period of time, water will be distributed to the farmers of ward no. 5 and 6 on the fixed hour rotational basis. Ward no. 5 farmers will get water from 12 noon to $6 \mathrm{PM}$ and ward no. 6 farmer will get water from 6 PM to 12 Noon of the next day.

During the focus group discussion with the users, it was found that these water management rules were strictly observed. These rules were evolved over time through learning process. WUA prepares the draft of water management rules, which are then endorsed by the General Assembly before they get enacted.

\section{Sustainability}

An irrigation system can't become sustainable unless it is owned by its users and benefits be realized and internalized as an integral part of their culture and livelihood. Sulitar Irrigation System from this standpoint is clearly on the avenue of sustainability. This system was initiated by the users by mobilizing resources for the construction and also for its operation and maintenance. For the last two decades, the farmers have been relentlessly working for the project. They have been contributing significantly in terms of cash and labor. WUA has institutionalized 
some mechanisms, which will make the system more robust and sustainable in the time to come. A maintenance worker has been positioned for the regular oversight of the system and to assure its smooth operation and maintenance. In order to remunerate the maintenance worker and for other sundry expenses, WUA has raised regular ISF @ NRs 600 per hectare. Additionally, WUA is realizing 20 labor days per hectare land per year for the repair and maintenance of the system. There is also provision of penalties to the defaulters violating these rules.

The major driving force that has inspired the WUA for the sustainability of this system is the incremental benefit they are reaping from the use of irrigation water. Food security and income level of the farmers of this system have increased significantly. Since the livelihood of the farmers dependent on this system has deeply embraced agriculture, irrigation is indispensable and its sustainability is and will be the prime concern of the users.

\section{Impact on Agriculture and Livelihood}

Most of the people residing in the command area of Sulitar Irrigation System depend on agricultural activities for earning their livelihood. Before commencing the service of Sulitar Irrigation System, they used to grow millet or similar low yield, low value crops or render their field fallow. Most of the time in a year, their land would remain fallow. Farming off-seasonal crops couldn't be imagined and sowing of crops would depend not on the crop calendar but on the monsoon onset events. With their own production, most of the farmers would survive for 3-6 months. Poverty and food insecurity was rampant in the whole community. People would work as laborer on development activities or other sectors in the nearby urban area. They would depend on the market for food for the most parts of a year. Now the fates of these farmers have changed. Since the construction of irrigation system, most of them are self reliant on their food needs. They are now able to grow off seasonal crops and vegetables. This has equipped them with employment and increased income opportunities. They have been able to enhance agricultural value chain. The formation of agriculture cooperatives resembles the value they have paid to commercialized agriculture and their effort for securing the supports and multiplying the benefits. Now, they have been advancing to market led commercial agriculture from the subsistence agriculture of the past. The flux of the change is not limited to the individual household level, but has sprayed to the overall area of that community. Health, nutrition and education status of people in this area has been found improved. Overall, socioeconomic status and livelihood of the people has transformed this community from poverty to prosperity.

\section{Conclusion}

Resources are critical to developing and maintaining an irrigation system. For the forward moving farmers like the users of Sulitar Irrigation System, resources can be developed, created and mobilized in a number of ways if the endeavor is driven by strong motivation and will power. The major challenges are of course maintaining accountability, transparency and equity, which lead to mutual trust and confidence among the users. Tens of thousands of FMISs in Nepal are running well, founded on these premises.

These systems are performing satisfactorily even better than large agency managed systems. However, there is possibility that once FMISs are intervened by external agencies, their system specific attributes and institutional dynamics may change. The traditional location specific norms and culture based organizations get transformed to the uniform organization framed by the agencies' policy. In the name of support interventions, FMIS are forced to follow the agencies' rules and regulations which might be different and even contradictory to their own. This is the very critical point that FMIS has to decide the trade-off between preserving their indigenous dynamism and resource mobilization cultures and receiving the one time resource support form agencies. Additionally, once the FMIS gets intervened by agencies, there is possibility of political interest or local elite's undue intervention. There is always higher chance of misuse of external resource than that they collect themselves. If it happens so unfortunately, seed of distrust and conflict will be sown which is, most probably, the cause of the chronic disease in the system that ultimately leads to cancer and no doctor can cure the situation. This is, therefore, a critical point that should be well thought over both by the farmers of the FMIS being intervened and the agency supporting the system in a good faith. Sulitar Irrigation System is also at this juncture. It's right time to ponder to maximize the external support for the system's improvement and to preserve its indignity and dynamism as well at the same time.

Krishna Prasad Rijal holds a Master Degree $(M S c)$ in Water Resources Engineering from Tribhuvan University, Nepal. At Present he is working as a Senior Divisional Engineer in Central Regional Irrigation Directorate under the Department of Irrigation, Government of Nepal since 2006. He has 12 years of experiences in Civil Engineering profession, especially in hydro sector. $\mathrm{He}$ is interested in research studies and training including project monitoring and evaluation technical designs. He is visiting faculty in National College of Engineering, Lalitpur, Nepal.

\section{Corresponding address: krishnarijal@gmail.com}

\section{References}

Agriculture Extension Directorate (AED), 2009, Department of Agriculture, Ministry of Agriculture Development, Cooperative based small irrigation scheme, small irrigation, fertilizer and seed transportation profile, 2009. (In Nepali Languge) 
CIDD-5 (Central Irrigation Development Division Number 5), 2015, an unpublished report: $S u b$ project preparation report, CMIASP-AF (Community managed Irrigated Area Sector Project-Additional Financing),Govt. of Nepal, Ministry of Irrigation, Department of Irrigation, ADB (Asian Development Bank) Manila, Philippines

Martin, E.D., 1986, Resource mobilization, water allocation and farmer agriculture in hill irrigation systems in Nepal. Unpublished Ph.D. dissertation, Ithaca, New Yoark, Cornelll University.

Paudel,T., 2010, Irrigation and poverty reduction, contribution, issues and prospects in Nepal, in
Pradhan p., Gautam U., Joshi N.M., edsDynamics of farmer managed irrigation systems: socioinstitutional, economic and technical contexts, proceedings of the fifth international seminar held on 25-26 March, 2010, Kathmandu, Nepal.,

Pradhan, P., 1989, Patterns of irrigation organization in Nepal, A comparative study of 21 farmer managed irrigation systems, International irrigation management institute.

Van Koppen, B., Parthasarathy, R., Safiliou, C., 2002, Poverty dimensions of Irrigation management transfer in large scale canals In Andhra Pradesh and Gujarat, India, research report 61,Colombo, Sri Lanka, International Water Management Institute. 